\title{
Mouth dissolving tablets- A unique dosage form curtailed for special purpose: a review
}

\author{
Waheeda Nasreen, Zahid Sadek Chowdhury, Yeakuty Marzan Jhanker, \\ Mohammad Fahim Kadir \\ Department of Pharmacy, University of Asia Pacific
}

\begin{abstract}
The concept of mouth dissolving tablets known as MDTs has emerged with an objective to improve patient's compliance. Methods to improve patient's compliance have always attracted scientists towards the development of fancy oral drug delivery systems. Among them, mouth dissolving drug delivery systems (MDDDS) have obtained an important position in the market by overcoming previously encountered administration problems and contributing to extension of patent life. These dosage forms rapidly disintegrate in contact with saliva even within $<60$ seconds, an attribute that makes them highly attractive for paediatric, geriatric, bedridden patients and for active patients who are busy and in travelling may not have access to water. This special dosage form has some prerequisite criteria for formulation and this also involves the use of special techniques for large scale industrial production. The aim of this article is to review the advantages and disadvantages of MDTs, common excipients used in the formulation especially highlighting the use of superdisintegrating agents and taste masking agents in formulation and finally the popular methods used to produce large scale tablets for commercial purpose.
\end{abstract}

Keywords- Drug delivery, Mouth dissolving tablets, Mucosal membrane, Superdisintegrant, Taste masking

\section{Introduction}

Many pharmaceutical dosages form are administered in the form of pills, granules, powder and liquid for conventional use. However, some patients, particularly paediatric and geriatric patients, have difficulty in swallowing or chewing solid dosage forms. Many paediatric and geriatric patients are unwilling to take these solid preparations due to a fear of bitter taste. In order to assist these patients, several mouth dissolving drug delivery systems have been developed.

The concept of mouth dissolving tablet also known as MDTs has emerged with an objective to improve patient's compliance. Methods to improve patient's compliance have always attracted scientists towards the development of fancy oral drug delivery systems. Among them, mouth dissolving drug delivery systems (MDDDS) have obtained an important position in the market by overcoming previously encountered administration problems and contributing to extension of patent life. These dosage forms rapidly disintegrate and/or dissolve to release the drug as soon as they come in contact with saliva even within $<60$ seconds, thus need for water during administration is avoidable, an attribute that makes them highly attractive for paediatric, geriatric, bedridden patients and for active patients and busy and travelling may not have access to water. Difficulty in swallowing conventional tablets and capsules is common among all age groups, especially in elderly and dysphagic patients. One study showed that $26 \%$ out of 1576 patients experienced difficulty in swallowing tablets due to their large size, followed by their surface, shape and taste [1,2]. Children may also have difficulty in ingesting because of their underdeveloped muscular and nervous systems other group that may experience problem using conventional oral dosage forms include mentally ill, the developmentally disable and uncooperative patients who refuse intake water or are nauseated; these problems can be resolved by means of Mouth Dissolving Tablets (MDTs). Mouth dissolving may also called fast dissolving tablets, melt-in-mouth tablets, orodispersible tablets, quick dissolving, rapid melts, porous tablets etc [1].

MDTs are known by various names such as ast-melting, fast-dissolving, oral disintegrating or orodisperse The European Pharmacopoeia defines the term orodispersible tablet "uncovered tablet for buccal cavity, where it disperses before ingestion" [2,3]. Suitable drug candidates for such systems include neuroleptics, cardiovascular agents, analgesics, anti-allergics and drugs for erectile dysfunction $[1,4]$. MDTs disintegrate and/or dissolve rapidly in saliva; therefore, water is not required during administration. Some tablets are designed to dissolve in saliva within few seconds, and are true fast-dissolving tablets. Others contain agents to enhance the rate of tablet disintegration in the oral cavity and are more appropriately termed as fastdisintegrating tablets, as they may take about one minute to disintegrate completely. Recently European Pharmacopoeia defines the term "Orodispersible tablet" as a tablet that to be placed in the mouth where it disperses rapidly before swallowing in less than three minutes [4]. 


\section{Prerequisite Criteria For Mouth Dissolving Tablets}

Oromucosal delivery, especially that utilising the buccal and sublingual mucosa as absorption site, is a promising drug delivery route which promotes rapid absorption and high bioavailability, with subsequent almost immediate onset of pharmacological effect. These advantages are the result of the highly vascularised oral mucosa through which drugs enter the systemic circulation directly, bypassing the gastrointestinal tract and the first pass effect in the liver [5].

Many factors are associated with mouth dissolving tablet delivery system. Among them one of the important criteria is that the drug has to be dissolved or disintegrate in the mouth within a few seconds. Moreover, the drug has to be soluble, stable and be able to penetrate the mucosal membrane so that to be absorbed. From manufacturing point of view, the drug should be compatible with taste masking, provide a pleasant mouth feel, leave no residue in the mouth after administration and most importantly be economically feasible for processing and subsequent packaging [6].

\section{Advantages Of Mouth Dissolving Tablets}

The first and foremost advantageous side for MDT is to achieve rapid absorption and high bioavailability associated with almost immediate onset of pharmacological action. This is achieved by avoiding first pass metabolism and decomposition from gastric acid [7]. Easily administered without having water to swallow the tablet proves to be a beneficial factor for patients who cannot swallow, such as elderly, stroke and bedridden patients; patients who should not swallow, such as renal failure patients; and who refuse to swallow, such as paediatrics, geriatric and psychiatric patients [8,9]. Besides, this provides additional safety by mitigating the risk of choking or suffocation during oral administration of conventional formulation due to physical obstruction. Patients suffering from motion sickness and others who experience sudden attack of allergy or coughing also find MDT as a useful alternative for treatment [10]. Mouth dissolving tablets also ensures stability for longer period of time compare to liquid dosage forms but ensures high bioavailability almost equal to that of liquid dosage forms. More efficient drug utilization (at lower doses) and avoidance of inactivation by liver metabolizing enzymes further increases the list of positive attributes of MDT [6].

\section{Disadvantages of Mouth Dissolving Tablets}

Patients have to stop eating, chewing, smoking, and possibly talking during drug therapy to keep the drug in sublingually [11, 12]. Swallowing part of the tablet before it is absorbed sublingually is also a potential problem. Demented or contrary patients who may feel foreign objects inside their mouth usually pull the tablet out before the active ingredients have been released from the formulation. Proper placement of the drug possesses another difficulty. Besides, drug cannot be used when the patient is unconscious. Sometimes intake of MDTs can result in tooth discoloration and decay may occur [6]. From formulation point of view, MDTs is hygroscopic in nature and therefore needed to be placed in dry place and it also requires special packaging for properly stabilization and safety of stable product $[13,14]$.

\section{Structure of Absorption Site}

The mucosa in the buccal cavity consist of non-keratinized structure with a thickness about 100-200 micrometer. Its normal turn over time is 20 days. It has a surface area of about 26.5 square $\mathrm{cm}$. Around $12.2 \mathrm{ml}$ of blood flows in $100 \mathrm{gm}$ of tissue per minute here. The average residence time of substances taken in oral cavity is poor but the permeability is very good due its high amount of blood supply [15].

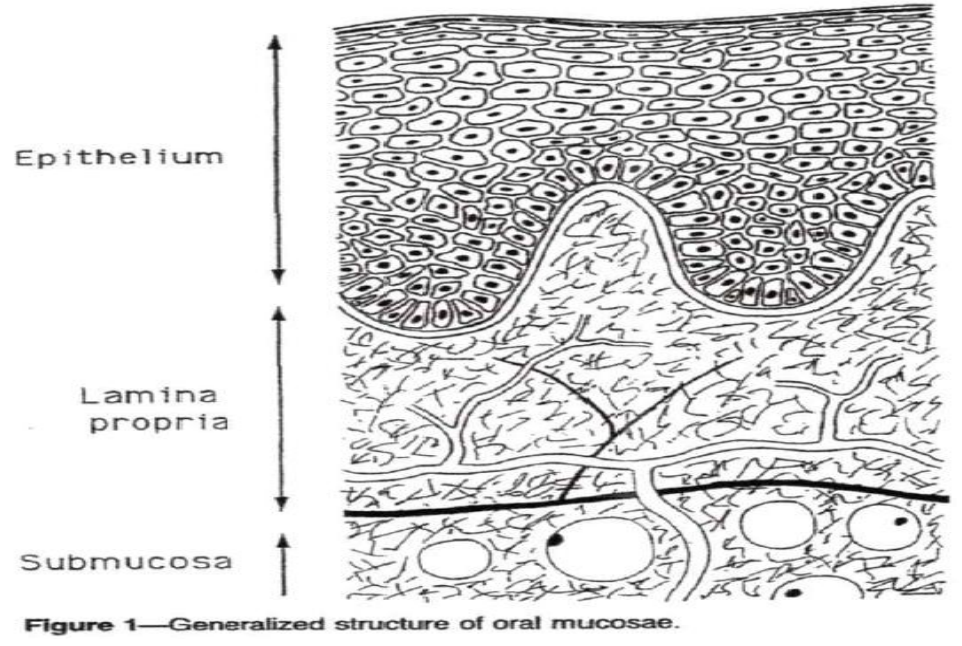

www.iosrjournals.org 


\subsection{Criteria of MDT}

\section{Formulation of MDT}

- Drug must dissolve or disintegrate quickly typically over 10-30 min period for effective absorption.

- $\quad$ Allowing the medicament to be rapidly absorbed.

- $\quad$ Should not be bitter tested

- $\quad$ Dose should be less than $20 \mathrm{mg}$.

- $\quad$ Should have small to moderate molecular weight.

- Should have good stability in water and saliva.

- $\quad$ Should be partially non ionized at oral cavities

\subsection{Influencing Factors for sublingual Absorption}

- Lipophilicity of Drug: For effective sublingual drug absorption the drug must have slightly higher lipid solubility for passive absorption.

- $\quad \mathrm{pH}$ and $\mathrm{pKa}$ of Saliva: The $\mathrm{pH}$ of saliva is 6.0.This $\mathrm{pH}$ is favorable for the drugs which remain unionized. For acidic drug pKa of saliva should be greater than 2.0 and for basic drug pKa of saliva should be less than 10.

- Solubility in salivary secretion: The drug should be soluble in aqueous buccal fluids.

- Binding to oral mucosa: Binding between drug and oral mucosa should be poor.

- Thickness of oral mucosa: The thickness of oral mucosa is 100-200 micrometer which is less as compared to buccal thickness (500-800 micrometer).

- Partition co efficient: The drugs which have oil to water partition co efficient within the value of 40-2000 are suitable for absorption through sublingually.

\subsection{Preformulation study of drugs}

- Particle size: Should be less than 5 micrometer.

- Porosity: Should be high for better absorption.

- Density: Should be low.

- Hardness: Should be low.

- Friability: Should be less than $1 \%$

- Drug Solubility: Aqueous solubility in various $\mathrm{pH}$ media is one of the most important properties of drug substance. These properties significantly affect the drug absorption and bioavailability.

- Disintegration time: The time for disintegration should be less than one min.[20]

\subsection{Common excipients used}

The mouth dissolving tablets usually have insufficient mechanical strength. Hence, careful handling is required, along with that the tablets may leave unpleasant taste and/or grittiness in mouth if not formulated properly. In recent past many technologies have been developed to improve the formulation and purpose of MDTs with very interesting features, like extremely low disintegration time, exceptional taste masking ability, pleasant mouth feel and sugar free tablets for diabetic patients [3].

Each technology has a different mechanism and some of them will be reviewed later in this article, and each fast-dissolving / disintegrating dosage form varies regarding the following:

* Mechanical strength of final product;

* Drug and dosage form stability;

* Mouth feel;

* Taste;

* Rate of dissolution of drug formulation in saliva;

* Swallow ability;

* Rate of absorption from the saliva solution;

* Overall bioavailability.

Excipients balance the properties of the actives in fast-melting tablets. This demands a thorough understanding of the chemistry of these excipients to prevent interaction with the actives. Determining the cost of these ingredients is another issue that needs to be addressed by formulators. The role of excipients is important in the formulation of fast-dissolving tablets. These inactive food-grade ingredients, when incorporated in the formulation, impart the desired organoleptic properties and product efficacy. Excipients are general and can be used for a broad range of actives, except some actives that require masking agents. 
The basic approach used in the development of the fast-dissolving tablet is the use of superdisintegrants, which permit the tablets for rapid disintegration. Superdisintegrants are generally used at a low concentration, typically $1-10 \%$ by weight relative to total weight of dosage unit [21].

Factors to be considered for selection of superdisintegrants:

- It should dissolving when tablet meets saliva in the mouth

- It should be compactable enough to produce less-friable tablets.

- It can able to produce good mouth feel to the patient. Thus, small particle size is preferred

- To achieve patient compliance.

- It should have good flow since it improve the flow-ability of the total blend.

Generally employed superdisintegrants are crosscarmellose sodium (Ac-Di-Sol), Crosspovidone (CP), sodium starch glycolate (SSG) etc. which represent example of crosslinked cellulose, crosslinked polymer and crosslinked starch respectively. Selection of appropriate excipients and manufacturing technology is necessary for obtaining the optimized design features of orally disintegrating dosage forms. Ideally, superdisintegrants should cause the tablet to disrupt, not only into the granules from which it was compressed but also into powder particles from which the granules were prepared [22]. Various natural substances gum karaya, modified starch and agar have been used in the formulations of fast disintegrating tablets. Mucilage of natural origin is preferred over semi-synthetic and synthetic substances because they are comparatively cheaper, abundantly available, non-irritating and nontoxic in nature [23].

Modified cellulose like crosscarmellose sodium, sodium starch glycolate, and crosspovidone were used to formulate and improve disintegration of nimesulide using vacuum drying technique, where in preliminary screening studies, the batch containing crosspovidone (2\%) showed the fastest disintegration, Camphor (20\%) containing tablets show evidence of faster disintegration as compared with tablets containing menthol and thymol [43], the percentage of camphor and crosspovidone has significant affect on disintegration time and percentage friability. But crosscarmellose, crosspovidone are unable to behave as superdisintegrant at high tablet crushing strength $[42,24]$. Another study revealed high superdisintegration potential of calcium salt of carboxymethylated (CaCOG) and carbamoylethylated (CaCEG) obtained from the seeds of Cassia fistula. $\mathrm{CaCOG}$ or $\mathrm{CaCEG}$ had been behaved as great potential superdisintegrants in the formulation of an antiemetic agent, Metoclopramide hydrochloride (MET) used mostly as prophylaxis of vomiting associated with cisplatin or other chemotherapeutic agents, they are directly compressible and revealed fast disintegrant (FDTs) with high mechanical strength and low DT [24].

Table 1: List of super disintegrants:

\begin{tabular}{|c|c|c|c|}
\hline Superdisintegrants & Examples & Mechanism of action & Special comments \\
\hline $\begin{array}{l}\text { Crosscarmellose } \AA \\
\text { Ac-Di-Sol® } \\
\text { Nymce ZSX® } \\
\text { Primellose } ® S o l u t a b ® \\
\text { Vivasol } ® L-H P C\end{array}$ & $\begin{array}{l}\text { Crosslinked } \\
\text { Cellulose }\end{array}$ & $\begin{array}{l}\text { Swells } 4-8 \text { folds } \\
\text { in }<10 \text { seconds. } \\
\text { Swelling and } \\
\text { wicking both. }\end{array}$ & $\begin{array}{l}\text { Swells in two } \\
\text { dimensions. } \\
\text { Direct compression or } \\
\text { granulation } \\
\text { Starch free }\end{array}$ \\
\hline $\begin{array}{l}\text { Crosspovidone } \\
\text { Crosspovidon } \mathrm{M} 囚 \\
\text { Kollidon } \AA \\
\text { Polyplasdone }{ }^{\circledR}\end{array}$ & $\begin{array}{l}\text { Crosslinked } \\
\text { PVP }\end{array}$ & $\begin{array}{l}\text { Swells very little } \\
\text { And returns to } \\
\text { original size } \\
\text { after compression } \\
\text { but act by } \\
\text { capillary action }\end{array}$ & $\begin{array}{l}\text { Water insoluble and } \\
\text { spongy in nature so get } \\
\text { porous tablet }\end{array}$ \\
\hline $\begin{array}{l}\text { Sodium starch glycolate } \\
\text { Explotab® } \\
\text { Primogel }{ }^{\circledR}\end{array}$ & $\begin{array}{ll}\text { Sodium } & \text { starch } \\
\text { glycolate } & \\
\text { Explotab } & \\
\text { Primogel }{ }^{\circledR} & \end{array}$ & $\begin{array}{l}\text { Swells } 7-12 \text { folds } \\
\text { in }<30 \text { seconds }\end{array}$ & $\begin{array}{l}\text { Swells in three } \\
\text { dimensions and high } \\
\text { level serve as sustain } \\
\text { release matrix }\end{array}$ \\
\hline $\begin{array}{l}\text { Alginic acid NF } \\
\text { Satialgine } ®\end{array}$ & $\begin{array}{l}\text { Crosslinked } \\
\text { alginic acid }\end{array}$ & $\begin{array}{l}\text { Rapid swelling in } \\
\text { aqueous medium } \\
\text { or wicking action }\end{array}$ & $\begin{array}{l}\text { Promote disintegration } \\
\text { in both dry or wet } \\
\text { granulation }\end{array}$ \\
\hline $\begin{array}{l}\text { Soy polysaccharides } \\
\text { Emcosoy® }\end{array}$ & $\begin{array}{l}\text { Natural super } \\
\text { Disintegrant }\end{array}$ & & $\begin{array}{l}\text { Does not contain any } \\
\text { starch or sugar. Used in } \\
\text { nutritional products. }\end{array}$ \\
\hline Plantago ovata & $\begin{array}{l}\text { Natural super } \\
\text { disintegrant }\end{array}$ & inert substance [23] & \\
\hline Calcium silicate & & $\begin{array}{l}\text { Wicking } \\
\text { action }\end{array}$ & $\begin{array}{l}\text { Highlyporous, } \\
\text { Optimum } \\
\text { concentration } \\
\text { between } \\
20-40 \%\end{array}$ \\
\hline
\end{tabular}




\begin{tabular}{|c|c|c|c|}
\hline $\begin{array}{l}\text { calcium salts of } \\
\text { carboxymethylated } \\
\text { (CaCOG) } \\
\text { carbamoylethylated } \\
\text { (CaCEG) derivatives of } \\
\text { Cassia fistula gum }\end{array}$ & $\begin{array}{l}\text { Carboxymethylated } \\
\text { C. fistula gum (CCG) }\end{array}$ & $\begin{array}{l}\text { lowest disintegration time } \\
\text { (DT) at highest } \\
\text { mechanical strength }\end{array}$ & $\begin{array}{l}\text { decreased water } \\
\text { sorption time without } \\
\text { effecting swelling } \\
\text { index and effective } \\
\text { pore radius (Reff.p) to } \\
\text { be the cause of } \\
\text { superdisintegration } \\
\text { potential }\end{array}$ \\
\hline Avicel PH 102 [24] & & $\begin{array}{l}\text { Absorb large amount of } \\
\text { water }\end{array}$ & Directly compressible \\
\hline $\begin{array}{l}\text { Sodium Starch Glycolate } \\
\text { (SSG) } \\
{[24]}\end{array}$ & & $\begin{array}{l}\text { Absorb large amount of } \\
\text { water }\end{array}$ & Directly compressible \\
\hline
\end{tabular}

Cosmetology lab of France team, has applied different approach in the formulation of MDT by using hydrophilic waxy binder (Superpolystate $\odot$, PEG-6-stearate) to improve sufficient mechanical integrity. Superpolystate $\odot$ is a waxy material with a melting point of $33-37{ }^{\circ} \mathrm{C}$ and an HLB value of 9 . So it will not only act as a binder and increase the physical resistance of tablets but will also help the disintegration of the tablets as it melts in the mouth and solublises rapidly leaving no residues. The incorporation of Superpolystate ${ }^{\circledR}$ in the formulation of RDT was realised by means of two different granulation methods: wet granulation by using an emulsion of this waxy binder as granulating liquid and melt granulation where the molten form of the binder was used [25]. The preparation and evaluation of fast disintegrating tablets by using different concentrations of natural superdisintegrant that is plantago ovata mucilage was studied. The reason for selecting plantago ovate mucilage is it has high swelling index. Mucilage of plantago ovata has various characteristics like binding, disintegrating and sustaining properties. Hence to formulate some long-acting formulation such as calcium channels blocker Amlodipine besylate [23]. Some agents due to their low bioavailability could not meet the therapeutic effect after oral administration; such as Domperidone- a widely used anti-emetic drug. Therefore fast dissolving tablet of domperidone hasb been developed with Avicel PH102 and Sodium Starch Glycolate by direct compression method and the formulation showed that in vitro drug release is not less than $95 \%$ within 30 minutes. So this formulation could meet patient's compliances for relief from emesis [24].

\subsection{Taste masking agents in MDTs formulation}

Along with fast disintegration the taste masking is also very important for the formulation of MDT, to achieve patient's compliance. Two approaches commonly utilised for taste masking; firstly by reducing solubility of the drug in the $\mathrm{pH}$ of saliva (5.6-6.8), secondly by altering the affinity and nature of drug which will interact with the taste receptor [44]. Number of natural and artificial taste masking agents has been evolved in the formulation of oro-dispersible tablet formulation. Mostly sweetening agent Aspartame (Quarrechin, France) is used as sweetening agent [25].

Table: 2 Taste masking agents (Flavours and sweeteners)

\begin{tabular}{|l|l|}
\hline Sl. No & Name \\
\hline 1. & Sodium phenolate \\
\hline 2. & Sod. bicarbonate, citric acid, orange/cream flavour \\
\hline 3. & Sod. bicarbonate, citric acid, lemon flavour \\
\hline 4. & Sod. citrate dihydrate, sod. saccharin, refined sugar \\
\hline 5. & $\begin{array}{l}\text { D-sorbitol, sodium saccharin, sodium glutamate, and } \\
\text { vanilla essence }\end{array}$ \\
\hline 6. & Sod. bicarbonate, citric acid, cherry flavour \\
\hline 7. & Starch, lactose, and mannitol \\
\hline
\end{tabular}

Table: 3 Taste masking agents (lipophilic vehicles)

\begin{tabular}{|l|l|}
\hline $\begin{array}{c}\text { Sl. } \\
\text { No }\end{array}$ & Name \\
\hline 1. & Hydrogenated oil and HPMC \\
\hline 2. & Molten stearyl stearate \\
\hline 3. & $\begin{array}{l}\text { Magnesium aluminum silicate \& } \\
\text { soyabean lecithin }\end{array}$ \\
\hline 4. & Glyceryl monostearate and AMCE \\
\hline 5. & Hydrogenated oil and surfactants \\
\hline
\end{tabular}

Note: HPMC=Hydroxypropyl methyl cellulose; $A M C E=$ aminoalkyl methacrylate copolymer 


\subsection{Freeze drying technology or lyophilization \\ VII. Technology Used In Manufacturing Of MDT}

It is one of the first generation techniques for preparing MDT which involves removal of solvent form a frozen solution or suspension of a drug and other additives [26]. The tablets produced have a very porous open matrix network into which saliva rapidly moves on after placing the tablet in the mouth. The formulations show enhanced dissolution characteristics due to appearance of glossy amorphous structure of the tablet. Drugs to be prepared by this technique should posses relative water insolubility with fine particle size and good aqueous stability in suspensions. Corvelen and Romen studied the influence of various formulation and process parameters to see the effect of lyophilization technique using hydrocholorothiazide. They concluded maltodextrins are useful in the formulation of MDT using freeze drying technique. The advantageous sides of this technique are processing the drug non elevated temperature thereby avoiding adverse thermal events. Lyophilization is relatively expensive and time consuming manufacturing process. Other drawback includes fragility, which make the use of conventional packing difficult and poor stability during storage under stressful condition [27].

\subsection{Tablet molding}

Molded tablets are prepared by using water soluble ingredients. The powder blend is moistened with hydro-alcoholic solvent and then compressed at low pressure in molded plates to form a wetted mass. Air drying is done to remove the solvent. Molded tablets are usually less compact then conventional tablet and therefore do not have the sufficient strength to endure insults during transportations. Another problem includes having a bitter taste characteristic. These problems can be solved by using proper binding and taste masking agents [26, 27]. To overcome poor taste masking characteristic Van Scoik incorporated drug containing discrete particles, which were formed by spray congealing a molten mixture of hydrogenated cottonseed oil, sodium bicarbonate, lecithin, polyethylene glycol and active ingredient into a lactose based tablet triturate form [27].

\subsection{Direct compression}

This is the simplest and most cost effective method to prepare MDT. The mixture of drug and other components are compressed without any preliminary treatment. Only a few drugs can be formulated by using this method. Usually a super disintegrate is used in the formulation which enhance the rate of disintegration and hence the rate of dissolution greatly. Tablet disintegration time can be optimized by concentrating the disintegrant. Below critical concentration tablet disintegration time is inversely proportional to the concentration of the disintegrating agent. However above critical concentration the disintegration time remains constant with the increase in concentration of disintegrant. The major drawback of effervescent excipients is their hygroscopicity. Another approach is to use sugar based excipients which demonstrate high aqueous solubility and provide pleasing mouth feeling. Commonly used excipients are dextrose, fructose. lactilol, maltilol, maltose, mannitol, sorbitol, starch hydrosysate, polydextrose and xylitol [27].

\subsection{Cotton candy process}

In this process a matrix of polysaccharide or saccharide is prepared by simultaneous action of flash melting and spinning. The matrix formed is then mixed with active ingredients and other excipients and finally compressed together to form MDTs. One of the patented technologies of this process is FLASHDOSE by Fuisz [28]. They have prepared ibuprofen as MDTs using this process.

\subsection{Sublimation}

Sublimation technology involves the incorporation of volatile inert solid compounds in the formulation and then compressed together to form tablets. The tablets formed are then subjected to sublimation which causes the inert substances to volatilize readily which left a porous tablet structure. This tablet when placed in the mouth readily dissolves in the saliva. The substances used are camphor, naphthalene, ammonium bicarbonate, ammonium carbonate, benzoic acid, hexamethylene tetramine, urea and urethane. Koizumi et al. applied the sublimation technique to prepare highly porous compressed tablets that were rapidly soluble in saliva [29]. Mannitol and camphor were used as a tablet matrix material and subliming the material respectively.

\subsection{Hardness}

\section{Parameters Of Sublingual Tablet Evaluation}

The test is done as per the standard methods. The hardness of three randomly selected tablets from each formulation is determined by placing each tablet diagonally between the two plungers of tablet hardness tester (with the nozzle) and applying pressure until the tablet broke down into two parts completely and the reading on the scale is noted down in $\mathrm{Kg} / \mathrm{cm}^{2}$. 


\subsection{Thickness}

The thickness of three randomly selected tablets from each formulation is determined in mm using a vernier caliper. The average values are calculated.

\subsection{Uniformity of Weight}

Weight variation test is done as per standard procedure. Ten tablets from each formulation are weighed using an electronic balance and the average weigh are calculated.

\subsection{Friability}

The friability of tablets using 10 tablets as a sample is measured using a Roche Friabilator. Tablets are rotated at $25 \mathrm{rpm}$ for 4 minutes or up to 100 revolutions. The tablets are then taken out, dedusted and reweighted. The percentage friability is calculated from the loss in weight as given in equation below. The weight loss should not more than $1 \%$.

$\%$ Friability $=($ initial weight- final weight $) \times 100$ (initial weight $)$

\subsection{Drug Content}

Ten randomly selected tablets from each formulation are finely powdered and fixed amount of powder is accurately weighed and transferred to $100 \mathrm{ml}$ volumetric flasks containing $50 \mathrm{ml}$ of phosphate buffer( $\mathrm{pH}$ 6.8 ) or $0.1 \mathrm{~N} \mathrm{HCl}$ solution. The flasks are shaken to mix the contents thoroughly and filtered. One $\mathrm{ml}$ of the filtrate is suitably diluted and drug content is estimated at $216.0 \mathrm{~nm}$ using a double beam UV-visible spectrophotometer. This procedure is repeated thrice and the average value is calculated.

\subsection{Wetting Time}

The tablets wetting time is measured by a procedure modified from that reported by Bi et al. The tablet is placed at the centre of two layers of absorbent paper fitted into a dish .After the paper is thoroughly wetted with distilled water, excess water is completely drained out of the dish. The time required for the water to diffuse from the wetted absorbent paper throughout the entire tablet is then recorded using a stopwatch.

\subsection{Water absorption ratio}

A piece of tissue paper folded twice is placed in a small Petri dish Containing $6 \mathrm{ml}$ of water. A tablet is put on the tissue paper and allowed to completely wet. The wetted tablet is then weighted. Water absorption ratio, $\mathrm{R}$ is determined using following equation.

$\mathrm{R}=100 \times \mathrm{Wa}-\mathrm{Wb} / \mathrm{Wa}$

Where, $\mathrm{Wa}=$ Weight of tablet after water absorption

$\mathrm{Wb}=$ Weight of tablet before water absorption

\subsection{In- vitro Disintegration Time}

Disintegration times for sublingual tablets are determined using USP tablet disintegration apparatus with phosphate buffer of $\mathrm{pH} 6.8$ or $0.1 \mathrm{n} \mathrm{HCl}$ as medium. The volume of medium is $900 \mathrm{ml}$ and temp is $37 \pm 2$ ${ }^{\circ} \mathrm{C}$. The time in seconds is taken for complete disintegration of the tablets with no palatable mass remaining in the apparatus is measured.

\subsection{In- vitro drug release study}

In-vitro release rate of sublingual tablets are carried out using United State Pharmacopoeia (USP) XXIV dissolution testing apparatus (Paddle method,busket method). The dissolution test is carried out using 900 $\mathrm{ml}$ of $6.8 \mathrm{pH}$ phosphate buffer or $0.1 \mathrm{~N} \mathrm{HCl}$, at $37 \pm 20 \mathrm{C}$ and $50 \mathrm{rpm}$. A sample $(5 \mathrm{ml})$ of the solution is withdrawn from the dissolution apparatus at different time intervals ( $\mathrm{min}$ ). The samples are replaced with fresh dissolution medium of same quantity. The samples are filtered and analysed for drug after appropriate dilution by UV spectrophotometer at respective wave length. The percentage drug release is calculated using an equation obtained from the calibration curve. [30]

\section{Literature Review}

Bayrak et al., demonstrated that zolmitrpatan- a serotonergic agonist when formulated as mucoadhesive tablet provides a good dissolution rate of greater than $80 \%$ within 2 minutes of administration. They investigated 10 different formulation using Chitosan as a mucoadhesive agent in the concentration of $0.5-5 \%$ and it was seen that $5 \%$ Chitosan provides the maximum $\mathrm{C}_{\max }$ values and minimum $\mathrm{t}_{\max }$ values when compared to subcutaneous dosage form [19]. 
In another study S. Bredenberg et al., studied the dissolution profile of sublingual fentanyl citrate using the drug from 100 microgram to 400 microgram. Granulated mannitol was used as a carrier molecule and crosslinked polyvinyl pyrrolidone was used as disintegrant and bioadhesive material. The formulation containing 100 and 200 microgram of fentanyl citrate had a dissolution rate of $80 \%$ within 1 minute and more than $95 \%$ within 5 minutes [41].

Table No. 4 Drugs used in the formulation of sublingual dosage forms

\begin{tabular}{|l|l|l|l|l|}
\hline Sl. No. & Drugs & Category & Dosage form & References \\
\hline 01 & Physostigmine Salicylate & Anti-alzheimers & Tablet & 31 \\
\hline 02 & Scopolamine & Opoid analgesic & Spray & 32 \\
\hline 03 & Captopril & Anti hypertensive & Tablet & 33 \\
\hline 04 & Furosemide & Diuretic & Tablet & 34 \\
\hline 05 & Nifedipine & Anti-anginal & Tablet & 35 \\
\hline 06 & Nitroglycerine & Anti-anginal & Tablet & 36 \\
\hline 07 & Vinpocetine & Neurotropic & Tablet & 37 \\
\hline 08 & Terbutaline Sulphate & Bronchodialator & Tablet & 38 \\
\hline 09 & Amlodipine Besylate & Antihypertensive & Tablet & 45 \\
\hline 10 & Ondanstron Hcl & Antiemetic & Film & 40 \\
\hline 11 & Buprenonpine & Opoid analgesic & Tablet & 16 \\
\hline 12 & Asenapine & Antiphychotic & Tablet & 16 \\
\hline
\end{tabular}

\section{Conclusion}

Mouth dissolving tablet provides a whole new arena of administering drugs through oral cavity without using any water. Mouth dissolving tablet can be considered as the best possible dosage form to be administered if the taste and dissolution pattern of the drug candidate can be improved. A huge amount of effort has already been given to produce more rapidly dissolving formulation. Efforts need to be given to improve the mucoadhesive nature of the tablet as this insures proper drug permeation through buccal mucosa. In the present review we identified several commercial manufacturing process of mouth dissolving tablets along with the common excipients used to formulate MDT with an emphasis on superdisintergrants and taste masking subustance. The installation and scale up of these instruments are very expensive and time consuming; so the price of the tablet is usually high than conventional tablet. Never the less, almost all type of drugs indicated for chronic use are either formulated as MDT or in the process of getting formulated. Introduction of this MDT dosage form in the market will improve the product range of the manufacturers and it will also help the physicians to prescribe this alternative dosage form to paediatric and geriatric patients where swallowing of the tablet posses a significant problem.

\section{References}

[1]. S Dali, C Subhashis, S Sanjay, M Brahmeshwar, Mouth Dissolving Tablets I: An Overview of Formulation Technology. Sci Pharm. 77, 2009, 309-326.

[2]. Y Okuda et al., A new formulation for orally disintegrating tablets using a suspension spray-coating. International Journal of Pharmaceutics. 382, 2009, 80-87.

[3]. TY Puttewar, MD Kshirsagar, AV Chandewar, RV Chikhale, Formulation and evaluation of orodispersible tablet of taste masked doxylamine succinateusing ion exchange resin. Journal of King Saud University (Science). 22, 2010, 229-240.

[4]. S Kamal, M Pooja, V Surender, S Navneet, K Ajay, Mouth dissolving tablets: An overview on future compaction in oral formulation. Technologies S Der Pharmacia Sinica. 1, 2010, 179-187.

[5]. AC Moffat, Absorption of drugs through the oral mucosa. Top. Med. Chem. 4, 1971,21-29.

[6]. D Bhowmik et al., Fast dissolving tablet: An overview. Journal of Chemical and Pharmaceutical Research. 1, 2009, 163-177.

[7]. NVM Satheesh, KS Ashok, S Pragati, S Kuldeep, NVS Madhav et al., Orotransmucosal drug delivery systems: A review. Journal of Controlled Release. 140, 2009, 2-11.

[8]. CG Wilson, N Washington, J Peach, GR Murray, J Kennerley, The behavior of a fast dissolving dosage form (Expidet) followed by g-scintigraphy. Int J Pharm. 40, 1987, 119-123.

[9]. JA Fix, Advances in quick-dissolving tablets technology employing Wowtab. Paper Presented at: IIR Conference on Drug Delivery Systems.1998 Oct.; Washington DC, USA

[10]. http://www.gsk.ca/english/docs-pdf/Zofran_2010.pdf

[11]. SR Parakh, AV Gothoskar, A review of mouth dissolving tablet technologies. Pharm Technol. 27, 2003, 92-100.

[12]. BS Kuchekar, CB Atul, HS Mahajan, Mouth dissolving tablets: a novel drug delivery system. Pharma Times. 35, 2003, 7-9.

[13]. R Chang, X Guo, BA Burnside, R Couch, Fast-dissolving tablets. Pharm. Tech. 24, 2000, 52-58.

[14]. LH Reddy, B Ghosh, Rajneesh, Fast dissolving drug delivery systems: a review of the literature. Indian J. Pharm. Sci. 64, 2002, 331336.

[15]. F Viralkuma, Patel et al., Advances in oral transmucosal drug delivery. Journal of controlled release. 153, 2011, 106-116.

[16]. Narang et al., Sublingual Mucosa as a route for Systemic drug delivery. International journal of pharmacy and pharmaceutical science. 3, 2011, 18-22.

[17]. L Lachman, HA Lieberman, JL Kanig, The Theory And Practice of Industrial Pharmacy, 3rd edition. (Verghese publishing House, Mumbai 1991) 333-335.

[18]. A Herbert. Lieberman, L Lachman, JB. Schwartz, Pharmaceutical Dosage Forms Tablet, (Informa Healthcare, London 1990 Volume 1) $334-335$. 
[19]. B Ziya, T Cetin, T Umut, E Halil, KO Cansel, SYAyhan, Formulation of zolmitriptan sublingual tablets prepared by direct compression with different polymers: In vitro and in vivo evaluation. European Journal of Pharmaceutics and Biopharmaceutics. 78, 2011, 499-505.

[20]. MA Calderón, P Rodriguez del Rio , P Demoly, Sublingual allergen immunotherapy in children: An evidence-based overview. Revue française d'allergologie. 52, 2012, 20-25.

[21]. http://www.pharmatutor.org/articles/a-review-on-fast-dissolving-tablet technology.

[22]. P Ashish, M.S Harsoliya., J.K Pathan, S Shruti, A Review- Formulation of Mouth Dissolving tablet. International Journal of Pharmaceutical and Clinical Science. 1, 2011,1-8.

[23]. G Gokul et al. Development and Characterisation of Fast Disintegrating Tablet of Amlodipine besylate using Mucilage of Plantago ovata as a Natural Superdisintegrant. Int.J. PharmTech Res. 3, 2011, 938-945.

[24]. J Fukami, B Yonemochi, Y Yoshihashi, KS Terada, Evaluation of rapidly disintegrating tablets containing glycine and carboxymethylcellulose. International Journal of Pharmaceutics. 310, 2006, 101-109.

[25]. RB Parmar et al., Formulation and Evaluation of Domperidone Fast Dissolving Tablets. Int.J. PharmTech Res. 1, 2009.

[26]. G. Abdelbary et al. The preparation of orally disintegrating tablets using a hydrophilic waxy binder. International Journal of Pharmaceutics. 278, 2004, 423-433.

[27]. FU Yourong, Y Shicheng, HJ Seong, K Susumu and P Kinam, Orally Fast Disintegrating Tablets: Developments, Technologies, Taste-Masking and Clinical Studies. Critical Reviews in Therapeutic Drug Carrier Systems. 21, 2004, 433-475.

[28]. P Priyank et al., Sublingual route for the systemic delivery of Ondansetron. Int. J. Drug Dev. \& Res. 3, 2011, 36-44.

[29]. R Fuisz. Ulcer prevention method using a melt-spun hydrogel. US Patent 5,622,717. 4, 1997.

[30]. K Koizumi et al., "New Method of Preparing Highly Porous Rapidly saliva Soluble Tablets by Sublimation Technique". Int. J. Pharm. 152, 1997, 127- 131.

[31]. V Bhardwaj, V Shukla, N Goyal, MD Salim, PK Sharma, Formulation and evaluation of fast disintegrating sublingual tablets of amlodipine besylate using different superdisintegrants. Int J Pharmacy Pharm Sci. 2, 2010, 89-92.

[32]. N Bolourtchian, N Hadidi, SM Foroutan, B Shafaghi, Development and optimization of sublingual tablet formulationfor Physostigmine Salicylate. Acta Pharm. 59, 2009, 301-312.

[33]. AM Al-Ghananeem, AH Malkawi, PA Crooks, Scopolamine sublingual spray: an alternative route of delivery for the treatment of motion sickness. Drug Dev Ind Pharm. 33, 2007, 577-582.

[34]. N Bolourtchian, N Hadidi, SM Foroutan, B Shafaghi, Formulation and optimization of captopril sublingual tablet using D-Optimal design. Iranian J Pharm Res.7, 2008, 259-267.

[35]. L Haegeli, HP Brunner-La Rocca, M Wenk, M Pfisterer, J Drewe, S Krahenbuhl, Sublingual administration of furosemide: new application of an old drug. B J Clin Pharmcol. 64, 2007, 804-809.

[36]. FR Sheeba, GD Acharya, S Rameshwari, AJ Jeya, Formulation and evaluation of nifedipine sublingual tablets. Asian J Pharm Clinical Res. 2, 2009, 44-48.

[37]. K Centkowska, M Sznitowska, Comparison of sublingual tablets with nitroglycerin complexed with $\beta$-Cyclodextrin or titrated with crosspovidone - Technological approach. Acta Pol Pharm-Drug Res. 65, 2008, 585-589.

[38]. MH Aburahma, HM El-Laithy, YE Hamza, Preparation and In Vitro/In Vivo Characterization of porous sublingual tablets containing ternary kneaded solid system of Vinpocetine with $\beta$-Cyclodextrin and hydroxy acid. Sci Pharm. 78, 2010, 363-379.

[39]. C Narendra, MS Srinath, PB Rao, Formulation and evaluation of sublingual tablet containing terbutaline sulphate: optimization and in vivo studies. Ars Pharm. 46, 2005, 138-158.

[40]. M Koland, VP Sandeep, NR Charyulu, Fast dissolving sublingual films of ondansetron hydrochloride: effect of additives on in vitro drug release and mucosal permeation. J Young Pharm. 2, 2010, 216-222.

[41]. S. Bredenger et al., In vitro and in vivo evaluation of a new sublingual tablet system for rapid oromucosal absorption using fentanyl citrate as the active substance. European Journal of Pharmaceutical Sciences. 20, 2003, 327-334.

[42]. RR Parshu, AK Tiwary, R Vikas, Superior disintegrating properties of calcium cross-linked Cassia fistula gum derivatives for fast dissolving tablets.

[43]. G Mukesh, P Madhabhai, An Avani, A Ruchi, D Rikita, B Nehal, Formulation Design and Optimization of Mouth Dissolve Tablets of Nimesulide Using Vacuum Drying Technique AAPS Pharm SciTech. 5, 2004, Article 36.

[44]. B Sagar, M Thoke, A Seminar on Taste Masking Methods in Pharmaceutical Formulations.

[45]. V Sutariya, R Mashru, M Sankalia, Development of fast dissolving sublingual film of salbutamol sulphate for acute asthmatic attack management: In vitro and In vivo study. AAPS Pharm Sci Tech. 2006. 